\title{
Preventing blindness: seeing is believing
}

I n Canada, an uncertain and fragmented approach to early detection and care of eye diseases results in preventable blindness. Loss of vision from all causes especially diabetic retinopathy, glaucoma, macular degeneration and cataracts - may not kill, but it is responsible for profound loss of quality of life. Costs to Canadians were estimated at $\$ 15.8$ billion in 2009 , and in subsequent years they will be substantially higher. ${ }^{1}$ Challenges worldwide are similar. But what are we going to do?

The uncertainty is owing to the imperfect and occasionally sparse evidence about the overall benefits of screening strategies. Fragmentation of care exists because highly skilled health professionals are in short supply, often not easily accessible and not well organized within our health system. As a result, early manifestations of blinding eye disease in the population go undetected. Indeed, by the time a patient notices that something is wrong, it may be too late.

Glaucoma afflicts $1 \%$ to $2 \%$ of Canadians over age 40 , half of whom only discover it once substantial visual loss and permanent optic nerve damage have occurred. ${ }^{2}$ But this disease has effective treatments that have been shown to slow the progress of illness. ${ }^{3}$ For this reason, strategies need to be devised to screen for asymptomatic disease.

However, easily implemented, population-based and costeffective screening strategies do not exist. Although some risk factors for glaucoma have been determined (age over 40 years, white or black race, a positive family history, diabetes mellitus and the presence of elevated intraocular pressure), we cannot even accurately identify patients at high risk or quantify that risk to inform further investigation and management.

Using intraocular pressure as a screening test exemplifies some of the many difficulties with current approaches and risk factors. ${ }^{4}$ Measuring intraocular pressure is inaccurate given the high degree of fluctuation in pressures. Indeed, glaucoma develops in only $10 \%$ of people who have raised pressures, and $40 \%$ of people who have early stage glaucoma do not have raised intraocular pressures. ${ }^{5}$ Complicating this picture is research suggesting that fluctuation of pressure is a risk factor independent of mean pressure. ${ }^{6}$ Furthermore, measurements require specialized technical skills and equipment.

What about screening with optic nerve imaging and peripheral visual field testing? Although the results are more accurate (and in the case of optic nerve imaging, directly visualize pathological changes), ${ }^{7}$ both methods are time consuming and require advanced equipment, training and skilled interpretation. In addition, studies have shown that screening with either method would need to be targeted to high-risk patients for cost-effectiveness ratios to fall below $\$ 40000$ per year per vision loss - a considerable expense. ${ }^{8}$ One mixed methods study suggested that all people over age 40 should be screened by either optic nerve photography or estimation of visual fields, with the potential addition of intraocular pressure measurements, but the authors conceded that such procedures would not be cost-effective.'

Other preventable eye diseases also need further studies to document whether screening leads to better long-term outcomes and how best to deliver such programs. Nonsurgical eye care seems to be split, without an overarching strategy, among optometrists, primary care physicians and, to a lesser extent, ophthalmologists, who are overwhelmed with procedures. Unfortunately, at the national and provincial levels, we have focused our attention on access to cataract surgery rather than on the early detection and treatment of other major eye diseases. This narrow targeting of resources and the lack of coordination have hampered progress in developing new, more collaborative models of care, such as regional eye diagnostic and imaging centres. Limited attempts to implement screening clinics in Canada and other countries seem to have been curtailed owing to cost barriers. ${ }^{10}$ Given Canada's aging population, the pressure is on to develop an integrated strategy underpinned by evidence.

To understand who and how to screen, we must invest more in the evaluation of effective screening and detection methods. Different models of early detection and care delivery ought to be piloted and the best ones implemented. More of the primary eye care should be rendered by other trained professionals such as optometrists. Primary care physicians can help with case identification while ophthalmologists provide leadership and consultation and perform the essential procedures.

A new vision is needed to devise accessible, effective and affordable eye care programs relevant to everyone. Getting the scientific basis right, and providing better integrated eye care services for screening would allow us all to see a clear way forward.

Ken Flegel MDCM MSc, Noni E. MacDonald MD MSc, Matthew B. Stanbrook MD PhD, Astika Kappagoda MBBS PhD, Paul C. Hébert MD MHSc

\section{References}

1. Cruess AF, Gordon KD, Bellan L, et al. The cost of vision loss in Canada. Can J Ophthalmol 2011;46:315-8.

2. Quigley HA. Glaucoma. Lancet 2011;377:1367-77.

3. Leske MC, Heijl A, Hussein M, et al. Factors for glaucoma progression and the effect of treatment: the early manifest glaucoma trial. Arch Ophthalmol 2003;121:48-56.

4. Singh K, Sit AJ. Intraocular pressure variability and glaucoma risk: complex and controversial. Arch Ophthalmol 2011;129:1080-1.

5. Shah R, Wormald RP. Glaucoma. Clin Evid (Online) 2011;pii:0703. PMID 21658300 . 


\section{EDITORIAL}

6. Caprioli J, Coleman AL. Intraocular pressure fluctuation a risk factor for visual field progression at low intraocular pressures in the advanced glaucoma intervention study. Ophthalmology 2008;115:1123-29.

7. Medeiros FA, Sample PA, Weinreb RN. Frequency doubling technology perimetry abnormalities as predictors of glaucomatous visual field loss. Am J Ophthalmol 2004; 137:863-71

8. Burr JM, Mowatt G, Hernández R, et al. The clinical effectiveness and costeffectiveness of screening for open angle glaucoma: a systematic review and economic evaluation. Health Technol Assess 2007;11:iii-iv,ix-x,1-190.

9. Burr JM, Campbell MK, Campbell SE, et al. Developing the clinical components of a complex intervention for a glaucoma screening trial: a mixed methods study. BMC Med Res Methodol 2011;11:54.

10. Harasymowycz P, Kamdeu Fansi A, Papamatheakis D. Screening for primary openangle glaucoma in the developed world: Are we there yet? Can J Ophthalmol 2005; 40:477-86
Competing interests: See www.cmaj.ca/site/misc/cmaj_staff.xhtml. None declared for Astika Kappagoda or Paul Hébert.

Affiliations: See www.cmaj.ca/site/misc/cmaj_staff.xhtml. Astika Kappagoda is with the Medical Journal of Australia. Paul Hébert is with the Ottawa Health Research Institute, Ottawa, Ont.

Correspondence to: CMAJ editor, pubs@cmaj.ca

Acknowledgements: The authors thank Bruce Jackson and Raymond LeBlanc, who provided expert opinion and reviewed the editorial for accuracy.

CMAJ 2012. DOI:10.1503/cmaj.111480 